\title{
The Wandering Charm Needle
}

\author{
Vimbai Chekenyere ${ }^{1 *}$, Emma Choon Hwee Lee ${ }^{1}$, Winston Eng Hoe Lim ${ }^{1,2}$, Nanda \\ Venkatanarasimha $^{1,2}$, Robert Chun Chen ${ }^{1,2}$ \\ 1. Division of Radiological Sciences, Singapore General Hospital, Singapore \\ 2. Duke-NUS Graduate Medicine School, Singapore \\ * Correspondence: Vimbai Chekenyere, Division of Radiological Sciences, Singapore General Hospital, Outram Road, 169608, \\ Singapore \\ (그vimbai.chekenyere@mohh.com.sg)
}

Radiology Case. 2020 Jun; 14(6):1-7 :: $\quad$ DOI: $10.3941 /$ jrcr.v14i6.3935

\begin{abstract}
Charm needles, otherwise known as susuk, are small pin like objects worn subcutaneously, thought to bring magic powers, bringing health, wealth, beauty, and other benefits to the wearer. These talismans are fairly common in South-East Asia, and are generally thought to be benign entities with few clinical sequela. In fact, no known complications have ever been reported in the literature, as susuk are typically composed of biologically inert precious metals and rarely migrate from their origin. Herein, we detail the first ever reported case of a complication from a charm needle, involving a middle aged Chinese female who had a charm needle subcutaneously inserted into the occipital scalp, which eventually migrated through the skull and into her left cerebellar hemisphere. Our aim is to familiarize readers to this peculiar phenomenon not widely practiced in the western world, and to highlight that charm needles are not as benign as initially conceived. To the best of our knowledge, this case demonstrates the first reported complication of a charm needle in the English medical literature.
\end{abstract}

\section{CASE REPORT}

\section{CASE REPORT}

We present a case of a 41-year old Chinese female with a longstanding clinical diagnosis of temporal lobe epilepsy as confirmed on an electroencephalogram (EEG) 15 years prior to her presentation. Over the following years she had multiple hospital admissions for break through seizures. Computed Tomography (CT) performed 12 years prior to present day showed no structural cause for her seizures (Figure 1a).

She presented to the Emergency Department 11 years ago after reported seizures with post ictal drowsiness. This CT scan showed a new linear 1x10 mm metallic foreign body in the left occipital scalp (Figure 1b). The scan was otherwise unremarkable. The patient denied any knowledge of this foreign body and did not complain of any pain in the region. She was discharged with a plan for outpatient follow-up of her epilepsy and foreign body. A subsequent follow up CT scan 5 years ago revealed interval migration of the foreign body through the occipital bone, which partially embedded in the left cerebellar hemisphere (Figure 1c).

In the same year, 5 years ago the patient underwent MRI of the brain (Figure 2) for progressive right sensorineural hearing loss. The brain was deemed unremarkable, except for a localized region of magnetic susceptibility signal in the left cerebellar hemisphere, corresponding to the linear metallic object seen on her previous CT scan. 
It was only via further clinical history and retrospective review of the imaging that the diagnosis of an errant charm needle was made. Throughout the patient's course, she refused any intervention for the intracranial foreign body as she lacked any localizing signs or symptoms corresponding to the metallic object. It is unclear how the charm needle may have migrated into the skull. Upon close inspection, the needle is angled relatively perpendicular to the occipital bone. One plausible theory is that prolonged external pressure upon the charm needle, perhaps exerted during sleep while the patient lay supine, may have facilitated the migration of the needle into the skull vault.

In her most recent imaging to date, the metallic foreign body was found stable in position (Figure 3 ).

\section{DISCUSSION}

\section{Etiology \& Demographics:}

Foreign bodies have been inserted into the human body for centuries. Some were placed for good luck or spiritual purposes, while others were placed for human mummification to prevent human decomposition [1]. As modern day medical practitioners, we often encounter foreign bodies that are intentionally placed to help the human body function more optimally: hip prostheses, metallic spinal rods, cardiac valves, intravenous lines and drainage catheters. However, there are foreign bodies that western medical practitioners may be less familiar with, categorized under the realm of cultural and alternative medical practices.

Charm needles, also known as susuk, are an example of such a non-traditional medical practice. This is a cultural phenomenon that involves embedding small metallic needles into the subcutaneous tissue, believed to bring beauty, health and success to the wearer. They were initially described in Muslim Malaysian females but are also found in Chinese and Indian people of both sexes. The practice is most commonly seen in the South East Asian countries of Thailand, Indonesia, Brunei, and Singapore [2,3].

Alternative medicine practitioners known as bo-mohs or shamans insert these charm needles classically via direct insertion under the skin $[2,3]$. This process involves a chanting ritual with massage of oil over the area of insertion. The procedure is painless with minimal or no bleeding [4].

\section{Clinical \& Imaging findings:}

The wearers must adhere to certain rules in order to preserve its power. Telling others of the charm needles presence is believed to strip its powers and wearers are warned by the bomohs to keep the talismans a secret [2]. Wearers are therefore very secretive and will often deny existence of the susuk. This coupled with the fact that charm needles are usually not clinically apparent on physical examination may pose a diagnostic challenge.
Charm needles are often found incidentally on imaging performed for other indications. They typically appear as linear metallic densities measuring $0.5-1 \mathrm{~mm}$ in diameter and 5-10 $\mathrm{mm}$ in length [2,3]. Variations in its appearance have been reported with previous published images showing a kink at its midpoint or a curvilinear U-shaped appearance [2,5]. Charm needles are usually composed of an alloy containing approximately $90 \%$ gold and copper $(10 \%)$ to harden its composition; smaller amounts of aluminum and silver may be present. Diamonds (Figure 4) and other non-metallic material such as fruits, betel leaves, turmeric, pepper and shallots have also been used as charm needles and these may be radiolucent making it difficult to diagnose on imaging $[2,3]$.

The number of charm needles inserted varies with previously reported numbers ranging from a single needle to up to 200 needles in different anatomical locations [3]. A few (1-5) scattered charm needles is generally the norm; common locations include the orofacial region, breasts, chest, abdomen, pubic region, and limbs on radiographs (Figure 5) [3].

We have also encountered a unique case of a single Malay female patient who presented for chronic abdominal bloatedness with chest and abdominal radiographs showing numerous charm needles in excess of 800 (Figure 6 and Figure 7).

Charm needles are generally thought to be benign entities not known to cause any adverse effects. Although gold is a relatively inert metal, with the process of insertion has the potential to introduce contaminants which could theoretically lead to infections [3]. However, we did not find any reports in the English medical literature on complications linked to charm needles [2] and our case is the first to report migration and embedment within the brain as a complication.

\section{Treatment \& Prognosis:}

The decision to undertake neurosurgical removal of metallic foreign bodies is controversial and involves the consideration of various factors [6]. If the foreign body is not causing any neurological symptoms, surgical removal may be avoided. For retained intracranial metallic objects causing epilepsy, surgical intervention may not be required if the seizures are able to be controlled with antiepileptic pharmacological therapy [2,7]. The size, mass, and location of the foreign body as well as the risk of infection are other factors to consider; a dense object in an eloquent area may be subject to migration in the intracranial cavity and serve as a nidus for intracranial infection, both of which could have devastating consequences [6]. Finally, the chemical composition of the foreign body determines whether it poses risks of toxin leakage. As with any surgery, removal is often challenging with risk of injury to vital neurological structures and thus the benefits should outweigh the risk [6].

With regard to the MRI safety profile of charm needles, a previous in vitro study has shown that no artefacts or distortions were caused by charm needles on a 1.5 Tesla MRI scanner. However, there have been no studies proving the safety profile of these needles in MRI scanners with higher 
magnetic field strengths [4]. In general, the decision to proceed with MRI imaging in the presence of known foreign bodies depends on the number of foreign bodies as well as whether they are located in the MRI scan region, both of which increase the theoretical risk of heating. Further, a metallic foreign body located in close proximity to vulnerable anatomical regions such as the orbits where migration could occur would be disastrous. In these scenarios, alternative modalities such as CT or ultrasound are usually preferred. In the event that imaging with MRI is felt to be crucial for clinical management, patients with foreign bodies are imaged with the lowest available Tesla MRI magnet [8]. Given the intracranial location of the charm needle in this case, the patient has been advised to avoid MRI in the future to prevent further migration of the foreign body.

\section{Differential Diagnosis:}

Although they have a characteristic imaging appearance, without prior knowledge, susuk have been mistaken for other radiopaque foreign bodies, such as deliberately implanted post-surgical material, dental restorative ins, root canal fillings, acupuncture, sewing and intravenous drug use needles[3,4,9]. Sewing needles have been shown in literature to be linked to cases of non-accidental injury with reported cases of needles inserted via the anterior fontanelle [7].

Case reports of one or several retained acupuncture needles embedded subcutaneously may appear similar to charm needles, yet they tend to be longer with lengths ranging from $7-200 \mathrm{mms}[10,11]$.

Embolisation of an intravenous needle fragment to the region of the heart has been reported and mistakenly thought to be a charm needle [9]. Questioning the patient for additional relevant clinical history is key to differentiate amongst the various possibilities.

\section{TEACHING POINT}

Charm needles are unique foreign bodies that are inserted subcutaneously into various parts of the body with potential complications of migration to critical anatomical structures and organs. While this cultural practice is largely confined to South-East Asia, with globalisation, charm needles will be increasingly be encountered by clinicians in the Western world. Therefore, better understanding of their imaging appearance and potential complications is required, especially amongst radiologists who will likely be the first to diagnose them.

\section{REFERENCES}

1. Villari N, Fornaciari G, Lippi D et al. The Medici Project: Radiographic Survey. Radiographics. 2009;29:2101-2115. PMID: 19926765

2. Thapasum A, Mohammed F. Susuk- Black magic exposed "White" by dental radiographs. Journal of Clinical and Diagnostic Research. 2014;8(7):3-4. PMID: 25177646

3. Jurkiewicz MT, Lim CC, Mohan S. Clandestine charisma of the charm needles: a radiologist's challenge. Emergency Radiology. 2017;24(4):427-430. PMID: 28417277

4. Varghese E, Samson RS, Nagraj SK, Chandrappa PR. Susuk or charm needle?: a strange object detected on orthodontic diagnostic radiographs. 2017;(11):1-2. BMJ Case Rep. PMID: 29092975

5. Martin JL, Vlachou PA. Case 263?: Malaysian Charm Needles ( Susuk ). Radiology. 2019;7(9): 1-5. PMID 30789811

6. Lanzino G, et al. An unusual foreign body in the brain. Barrow Quarterly. 2002; Vol 18:1. Available at: https://www.barrowneuro.org/education/grand-roundspublications-and-media/barrow-quarterly/volume-18-no-12002/unusual-foreign-body-brain/. (Accessed: 8 March 2020).

7. Yurekli VA, Dogan M, Kutluhan S, Koyuncuoglu HR. Status epilepticus in a 52-year-old woman due to intracranial needle. Seizure. 2012;21: 652-654. PMID: 22743099

8. Frank SG. Metallic Foreign Bodies, Reference Manual for Magnetic Resonance Safety, Implants and Devices. Edited by Karacozoff M. A. pages 83-87 2017th edn. Los Angeles California. ISBN 978-0-9891632-4-8.

9. Teo LL, Seto KY, Chai P, Venkatesh SK. Embolised injection needle fragment to the heart, Mimicking a subcutaneous charm needle. Annals of the Academy of Medicine Singapore. 2010;39(6):499-500. PMID: 20625631

10. Xu S, Wang L, Cooper E, et al. Adverse Events of Acupuncture?: A Systematic Review of Case Reports. Evid Based Complement Alternat Med. 2013(1) PMID: 23573135

11. Lazarow F, Andrews RH, Revels J, Shaves S. ScienceDirect Migration of innumerable chronically retained acupuncture needles. Radiology Case Reports. Elsevier Inc, 2017;12(3):546-548. PMID: 28828123 


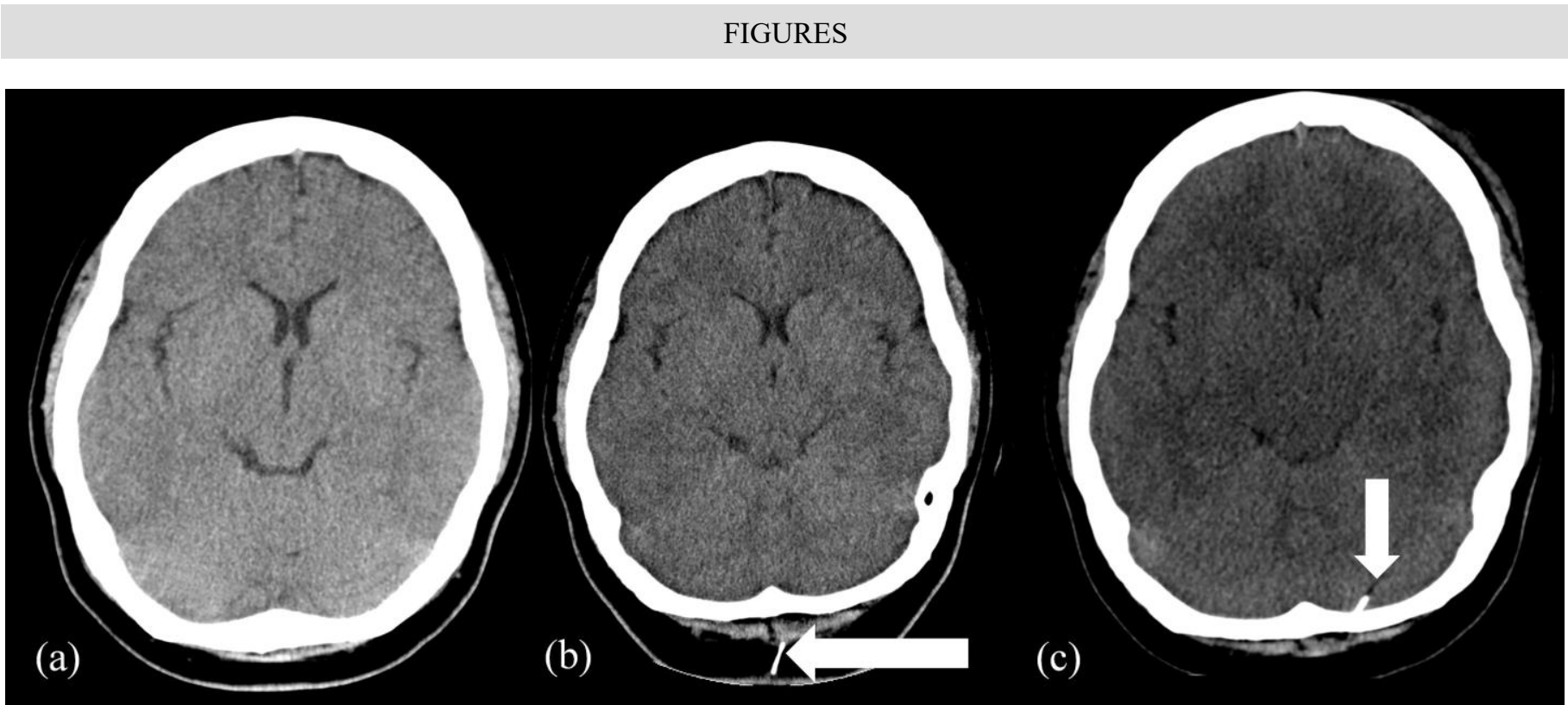

Figure 1: 41 year old Chinese female with seizures

FINDINGS: Non contrast CT brain in axial planes (a-c), shows progressive migration of the foreign body (white solid arrow)

(a) 12 years ago, seizures present with no foreign body detected.

(b) 11 years ago, new linear metallic foreign body (white solid arrow) in the occipital scalp tissues.

(c) 5 years ago, interval migration of the foreign body into the left cerebellar lobe (solid white arrow).

\section{TECHNIQUE}

Figure (a): Philips Mx800QUAD 249mAs, 125mAs, 120kV: Axial non-contrast, 5mm slice thickness

Figure (b): TOSHIBA Asteion scanner $125 \mathrm{mAs}, 120 \mathrm{kV}$ : Axial non-contrast, 5mm slice thickness

Figure (c): Philips iCT 256 scanner, 321mAs, 120kV, Axial non contrast, 3mm slice thickness.

Figure 2 (right): 41 year old Chinese female with sensorineural hearing loss

FINDINGS: MRI brain performed in the same year with axial T2WI of the brain shows focal magnetic susceptibility in the left cerebellar lobe (white solid arrow) corresponding to the previously seen foreign body.

TECHNIQUE: 1.5 Tesla scanner (Siemens Avanto), $7 \mathrm{~mm}$ interslice gap, TE for T2W 110, TR for T2WI 5050.

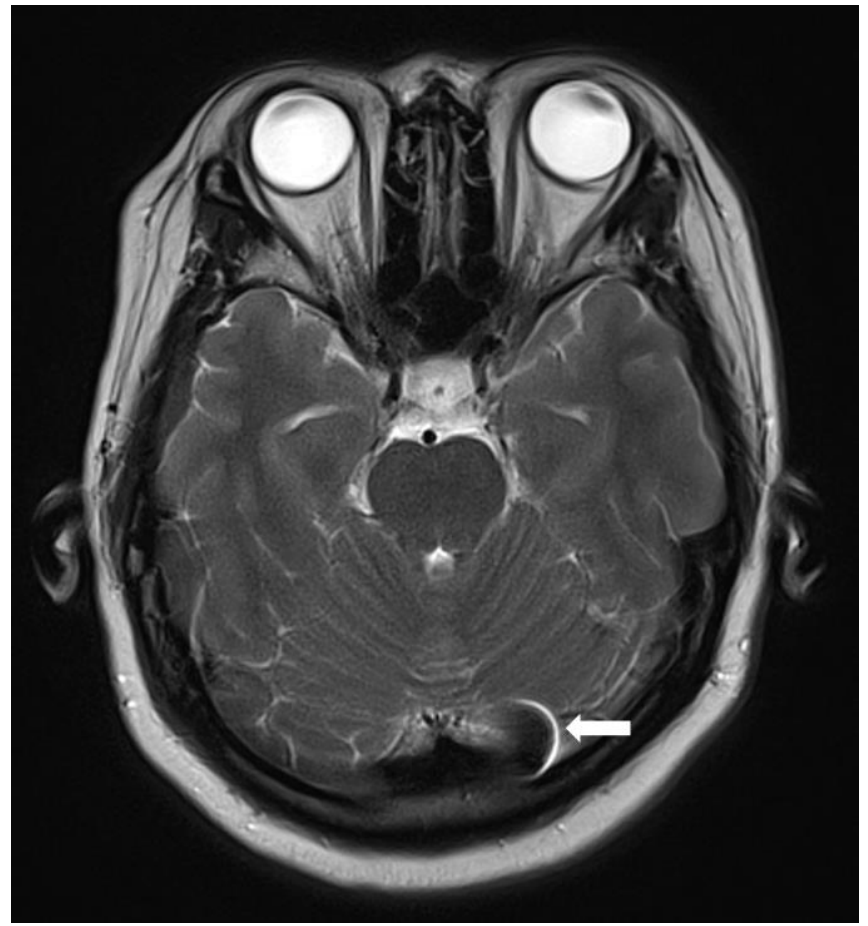




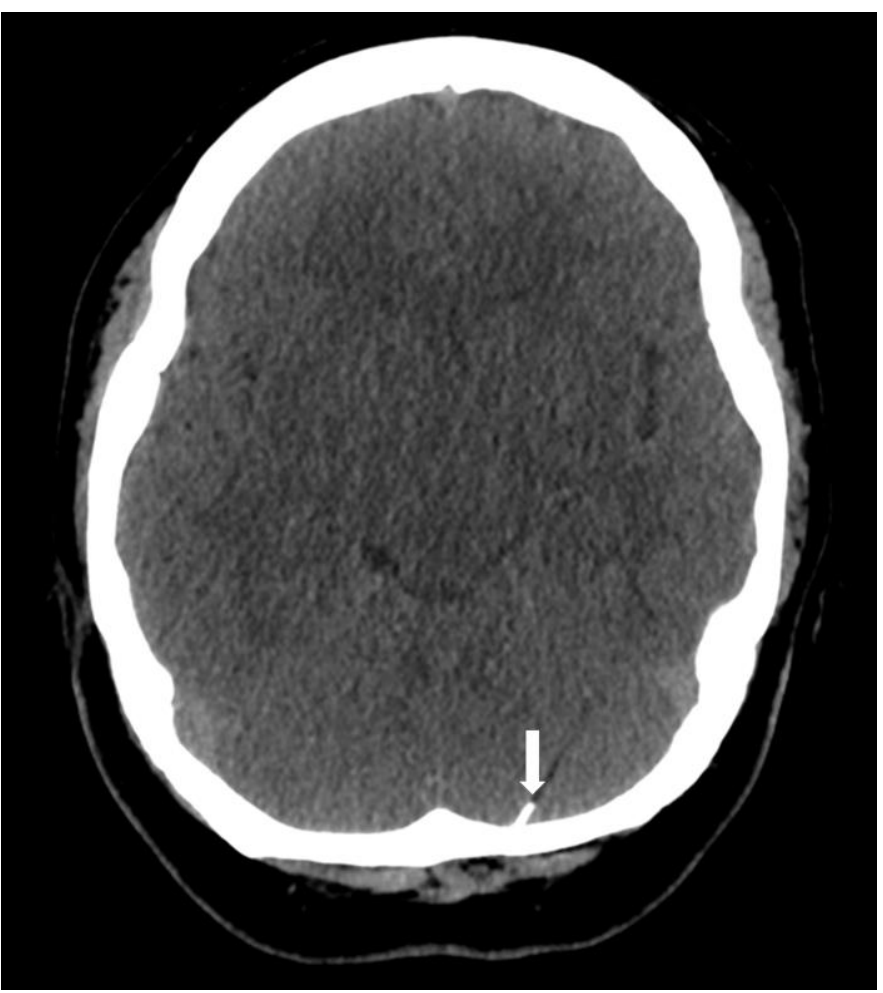

Figure 3 (left): 41 year old Chinese female with headache

FINDINGS: Follow up non-contrast CT three years later in axial plane showed stable position of the linear metallic foreign body (solid white arrow) in the left cerebellar lobe.

TECHNIQUE: Siemens Somatom Definition Flash CT scanner Axial non contrast, $3 \mathrm{~mm}$ thickness

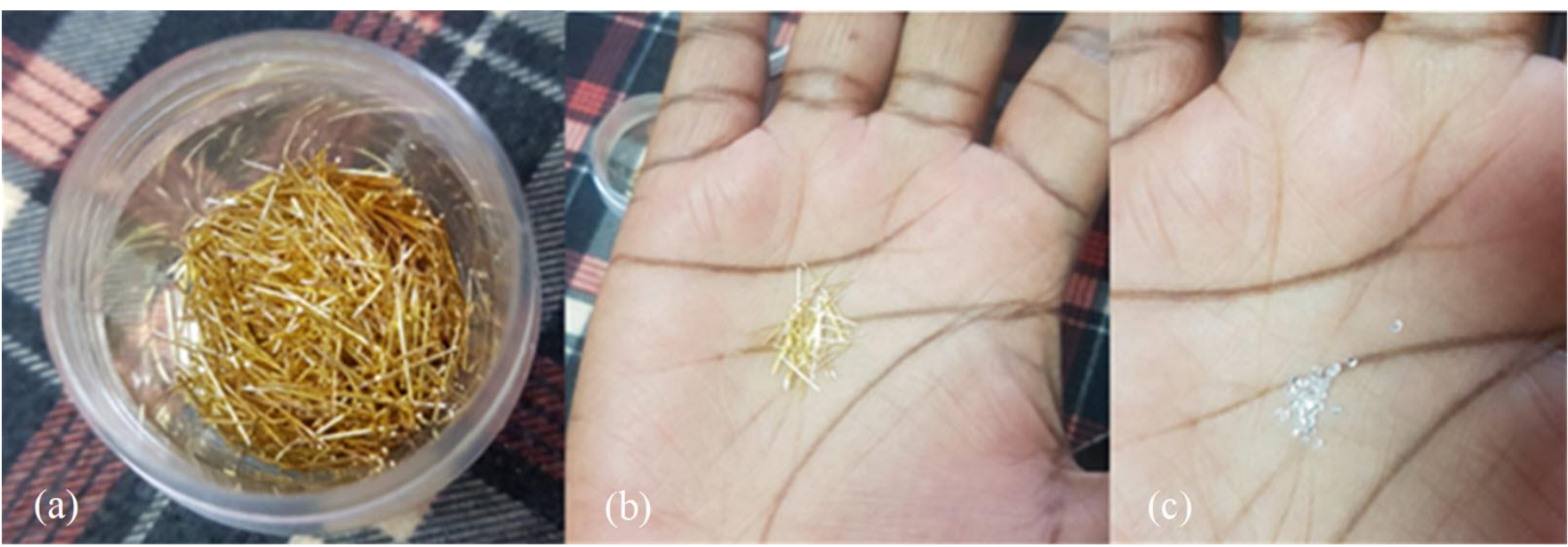

Figure 4: Charm needles in Singapore, Gold (Fig a and b) and diamond (Fig c). 


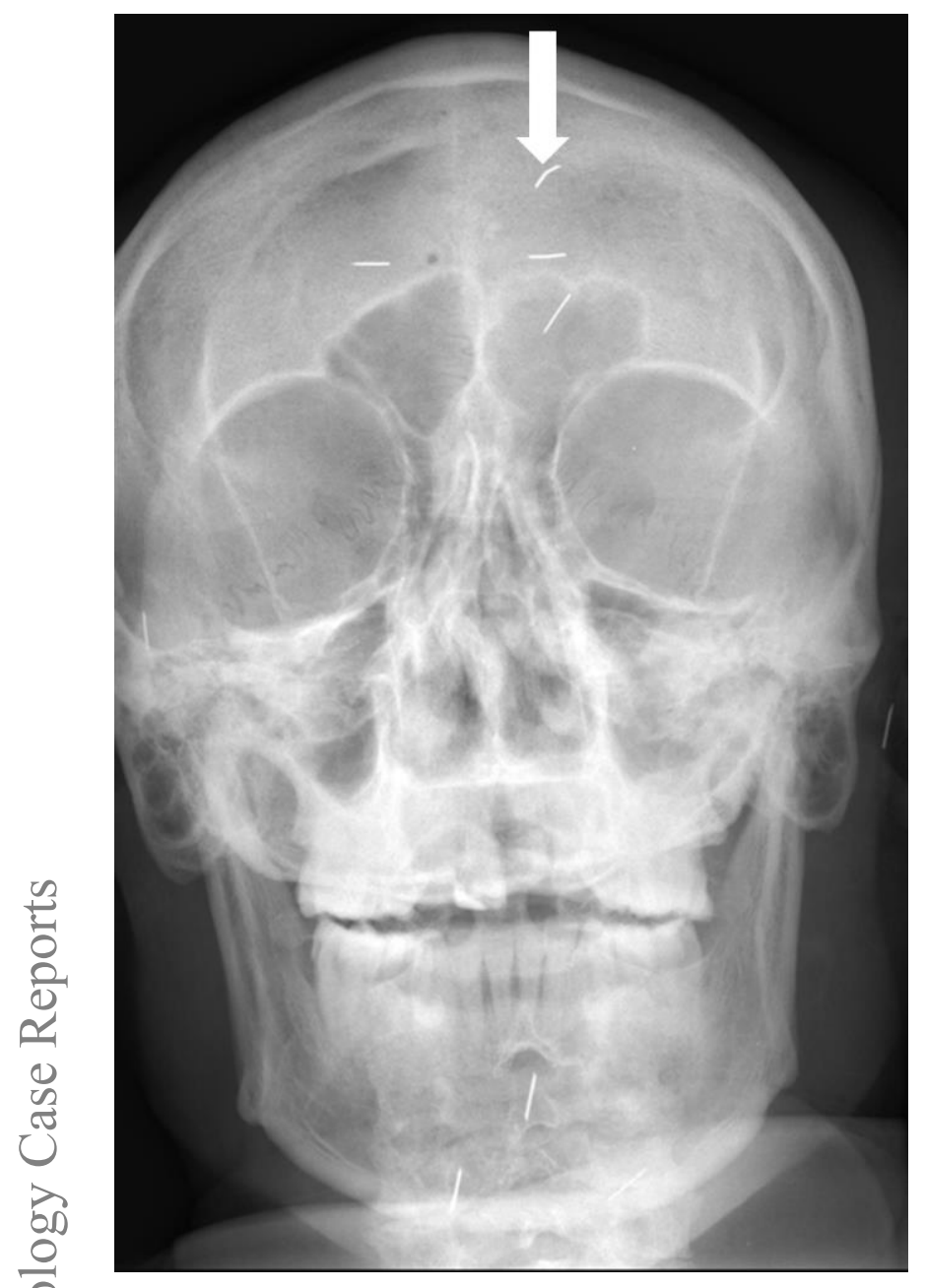

Figure 5: 44 year old Malay male with a history of a fall.

FINDINGS: Scattered linear opacities representing charm needles over the frontal, maxillary and mandibular regions.

TECHNIQUE: FUJIFILM Corporation facial bone x-ray

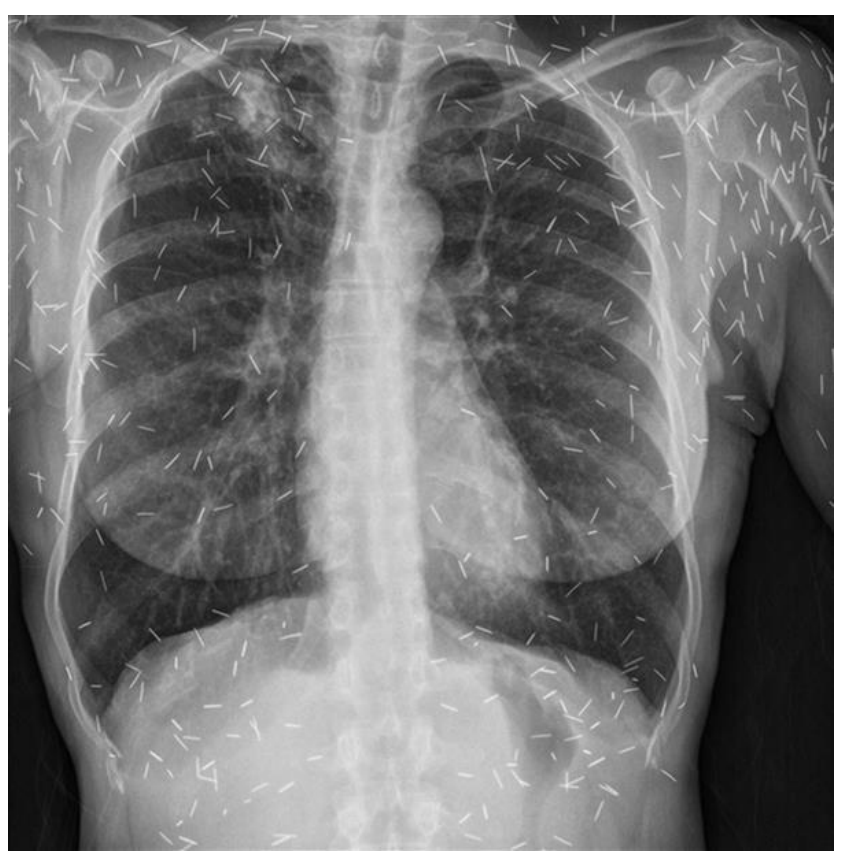

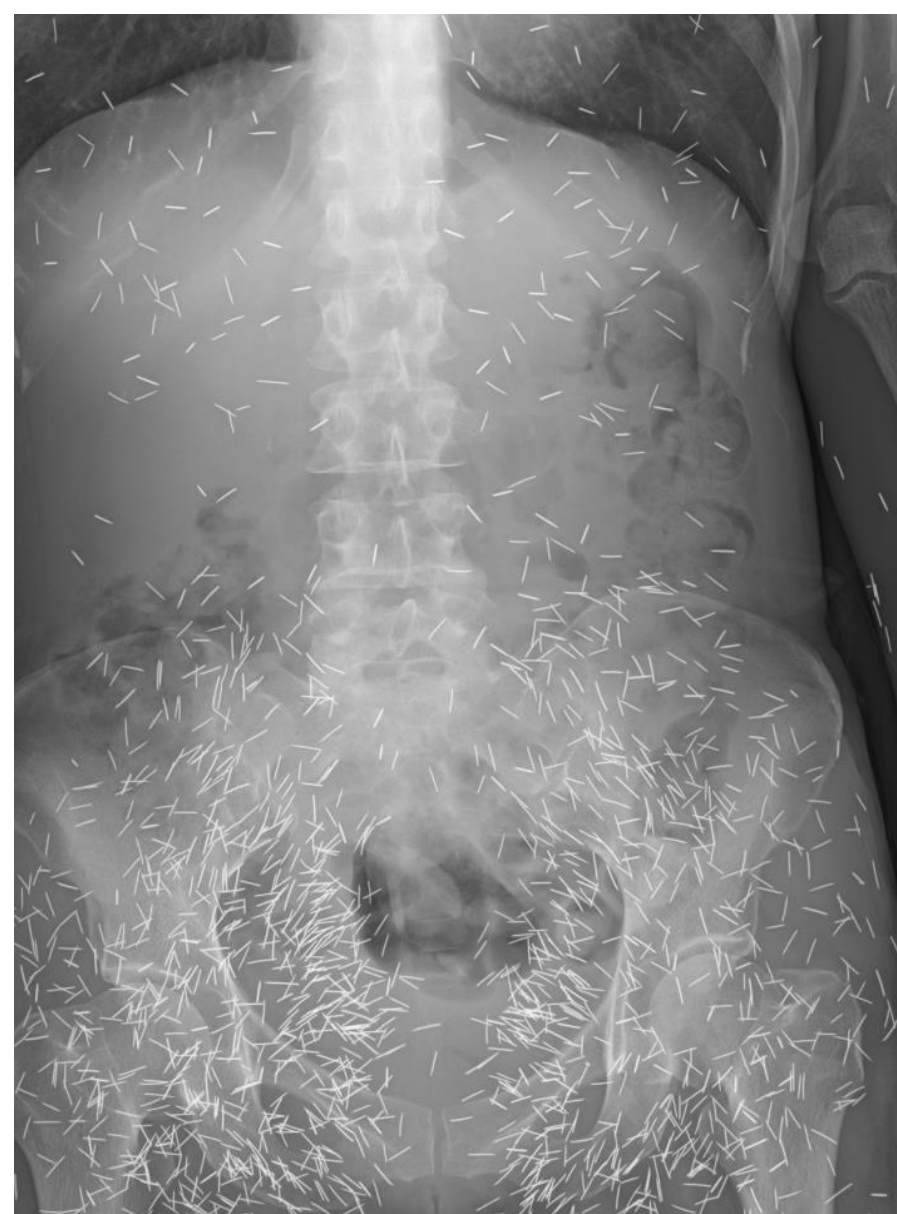

Figure 7: 55 year old Malay female with chronic abdominal bloatedness.

FINDINGS: Abdominal radiograph of the same patient shows multiple linear densities compatible with charm needles are projected over the soft tissues, most prominent or extensive over the pelvis.

Figure 6 (left): 55 year old Malay female with chronic abdominal bloatedness.

FINDINGS: Chest radiograph shows multiple linear densities projected over the thorax representing charm needles.

TECHNIQUE: SIEMENS Flurospot compact FD chest x-ray posteroanterior (PA). 


\begin{tabular}{|l|l|}
\hline Etiology & South East Asian cultural practice \\
\hline Anatomical location & Subcutaneous \\
\hline Imaging finding & Short linear metallic density \\
\hline Management & Surgical removal often avoided. \\
\hline Prognosis & Rarely found to complicate \\
\hline
\end{tabular}

Table 1: Summary table for charm needles.

\begin{tabular}{|l|l|l|l|}
\hline Differential diagnosis & Clinical features & Location & Imaging Appearance \\
\hline Charm needle & $\begin{array}{l}\text { Not clinically apparent and } \\
\text { patient may be secretive }\end{array}$ & Orofacial, chest and abdomen & $\begin{array}{l}0.5-1 \text { mm in diameter and 5-10 } \\
\text { mm in length }\end{array}$ \\
\hline Root canal fillings & Dental implant history & Orofacial & $\begin{array}{l}\text { Variable but taper with root canal, } \\
\text { may fuse with crown. }\end{array}$ \\
\hline $\begin{array}{l}\text { Implant post-surgical } \\
\text { material }\end{array}$ & Previous surgery & Post-surgical bed & Variable \\
\hline $\begin{array}{l}\text { Broken acupuncture } \\
\text { needles }\end{array}$ & Relevant history & Any anatomical location & $\begin{array}{l}\text { Length ranging from 7 - 200 } \\
\text { mms. }\end{array}$ \\
\hline $\begin{array}{l}\text { Sewing needles } \\
\text { Intravenous drug use } \\
\text { needles }\end{array}$ & $\begin{array}{l}\text { History of non-accidental injury } \\
\text { abuse }\end{array}$ & Anywhere & $\begin{array}{l}\text { Linear with 1 tip showing a } \\
\text { solitary hole. }\end{array}$ \\
\hline
\end{tabular}

Table 2: Differential diagnosis table for charm needles.

\section{ABBREVIATIONS}

CT $=$ Computed Tomography

Fig $=$ Figure

MRI = Magnetic resonance imaging

$\mathrm{PA}=$ Posteroanterior

\section{Online access}

This publication is online available at:

www.radiologycases.com/index.php/radiologycases/article/view/3935

\section{Peer discussion}

Discuss this manuscript in our protected discussion forum at www.radiolopolis.com/forums/JRCR

\section{Interactivity}

\section{KEYWORDS}

Charm needle; Susuk; Foreign bodies; Radiology

\section{ACKNOWLEDGEMENTS}

Master Sribala Nair- for illustrative photos of charms and interview. Mei Fang Tay. Li Rong Yin. All the other MRI radiographers in Singapore General Hospital Radiological Sciences Division.
This publication is available as an interactive article with scroll, window/level, magnify and more features.

Available online at www.RadiologyCases.com

\section{Published by EduRad}

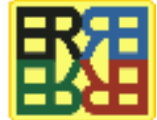

www.EduRad.org 